\title{
Biochemical and structural characterization of C-terminal constructs of bovine soluble guanylate cyclase
}

\author{
Franziska Seeger*, Elsa D Garcin \\ From 5th International Conference on cGMP: Generators, Effectors and Therapeutic Implications \\ Halle, Germany. 24-26 June 2011
}

\section{Background}

Soluble guanylate cyclase (sGC) is the key enzyme in the NO-sGC-cGMP signaling cascade crucial in regulating the cardiovascular system. Low output of this system causes hypertension and acute heart failure, which are the leading causes of death globally.

Mammalian sGC is a heterodimer. Each of the two homologous subunits $(\alpha$ and $\beta$ ) contains three domains: an N-terminal regulatory domain (HNOX: Heme Nitric oxide OXygen), a central dimerization HNOX associated (HNOXA) and coiled-coil (CC) domain, and a C-terminal catalytic domain (GC).

The enzyme is basally active, but NO binding to the heme group in the $\beta$ subunit's regulatory domain enhances sGC catalytic output several hundred fold.
The exact mechanism by which the regulatory domain relays the NO activation signal to the catalytic domain remains elusive. Furthermore, it has been proposed that the HNOX regulatory domain inhibits the activity of the catalytic GC domain [1]. Winger et al. showed that the GC heterodimer by itself exhibits catalytic activity in the presence of $\mathrm{Mg}^{2+}$ and $\mathrm{Mn}^{2+}[1]$. On the contrary, Wedel et al. propose that additional amino acids are required for dimerization, folding, and catalytic activity [2].

We aim to test the hypothesis that additional domains are necessary for full activity of the catalytic domain by combining mutagenesis, activity assays, fluorescence spectroscopy, Small-Angle X-ray Scattering (SAXS), and protein crystallography.

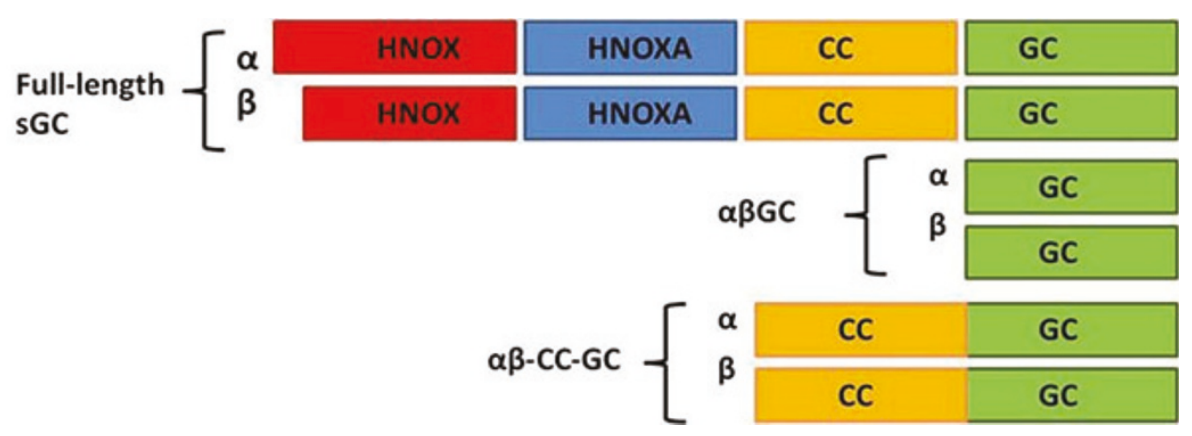

Figure 1 Full-length sGC and C-terminal truncated constructs $\alpha \beta G C$ and $\alpha \beta C C-G C$.

\footnotetext{
* Correspondence: fseeger1@umbc.edu

Department of Chemistry Biochemistry, University of Maryland Baltimore

County, Baltimore MD 21250, USA
} 


\section{Results}

We have chosen a divide-and-conquer approach to study sGC catalysis. Here, we report the recombinant expression and purification of bovine C-terminal constructs " $\alpha \beta G C$ " and " $\alpha \beta C C-G C$ " in E. coli (Figure 1 ). Preliminary activity measurements for these constructs in the presence of $\mathrm{Mg}^{2+}$ show that $\alpha \beta C C-G C$ exhibits higher level of catalytic activity than $\alpha \beta G C$ (4-fold). This suggests that additional domains are necessary for full catalytic activity. To our knowledge this is the first report that attributes catalytic activity to the $\alpha \beta C C-G C$ heterodimer in the presence of $\mathrm{Mg}^{2+}$.

\section{Conclusion}

The C-terminal sGC constructs $\alpha \beta G C$ and $\alpha \beta C C$-GC, both exhibit catalytic activity in the presence of $\mathrm{Mg}^{2+}$. Higher levels of activity of $\alpha \beta C C-G C$ as compared to $\alpha \beta G C$ hint at structural differences between the two constructs that will be characterized using protein X-ray crystallography and small-angle X-ray scattering.

\section{Acknowledgements}

Work supported by American Heart Association Scientist Development Grant (E. Garcin) and NIH CBI Training Grant NIH T32 GM066706-06.

Published: 1 August 2011

\section{References}

1. Winger JA, Marletta MA: Expression and characterization of the catalytic domains of soluble Guanylate cyclase: interaction with the heme domain. Biochemistry 2005, 44:4083-4090.

2. Wedel B, Koesling D: Functional domains of soluble guanylyl cyclase. Biol Chem 1995, 270:24871-24875.

\section{doi:10.1186/1471-2210-11-S1-P67}

Cite this article as: Seeger and Garcin: Biochemical and structural

characterization of C-terminal constructs of bovine soluble

guanylate cyclase. BMC Pharmacology 2011 11(Suppl 1):P67.

\section{Submit your next manuscript to BioMed Central} and take full advantage of:

- Convenient online submission

- Thorough peer review

- No space constraints or color figure charges

- Immediate publication on acceptance

- Inclusion in PubMed, CAS, Scopus and Google Scholar

- Research which is freely available for redistribution

Submit your manuscript at www.biomedcentral.com/submit 